\title{
AN UNUSUAL CASE OF A-V NODAL RHYTHM WITH VARYING A-V BLOCK
}

\author{
BY \\ ERNST SIMONSON AND NORBERT ENZER
}

From the Research Laboratory of Mount Sinai Hospital, Milwaukee, Wis., U.S.A.

Received October 12, 1944

In the human electrocardiogram, A-V block prolongs the $\mathrm{P}-\mathrm{R}$ interval to values exceeding 0.2 sec., while nodal rhythm is characterized by $P-R$ intervals ranging from approximately plus 0.12 to minus $0.19 \mathrm{sec}$. (R-P intervals). The simultaneous occurrence of both A-V block and nodal rhythm may produce $P-R$ intervals within normal range $(0 \cdot 12$ to $0 \cdot 2)$; however, this condition can be recognized by the characteristic retrograde $P$ wave pattern (inversion of P II and P III), as recently shown by Langendorf, Simon, and Katz (1944). As the authors point out, this does not exclude the presence of A-V block.with $\mathrm{P}-\mathrm{R}$ intervals between plus $0 \cdot 12$ and minus $0 \cdot 19$. Since delay or even complete blockage of the A-V nodal impulse may occur on its way to the ventricles (antegrade block) as well as to the auricles (retrograde block) (Lewis, 1914; Lewis, White, and Meakins, 1914; Drury, 1924; and Scherf, 1926), any combination of $\mathrm{P}-\mathrm{R}$ or $\mathrm{R}-\mathrm{P}$ interval is compatible with the simultaneous existence of A-V block and nodal rhythm. The relation between $\mathrm{P}$ and $\mathrm{R}$ depends on the site of impulse formation and the site and the degree of the block.

It is possible that in partial A-V block the site of impulse formation and that of the block are such that the antegrade impulse to the ventricles arrives simultaneously or earlier than the retrograde impulse to the auricles. This has been illustrated by Langendorf et al. (1944) in a scheme, but, naturally, this can not be easily demonstrated in actual tracings. The authors present cases with $\mathrm{P}-\mathrm{R}$ intervals greater than $0 \cdot 12 \mathrm{sec}$.

The case presented in this paper is a further contribution to this problem because it illustrates a type of arrhythmia, apparently rare, since we have not seen it reported in recent years.

Case report. The patient, a woman of 81 years, had a history of heart disease for 45 years. With repeated digitalization she had been without complaints for the past three years. She was admitted to hospital on 26/12/43 because of dyspnœa. She had no precordial pain although there was a feeling of precordial oppression. There was no cyanosis, no palpitation, nor œdema. The blood pressure was $160 / 110$. The heart was enlarged to the left; the heart sounds were inaudible, due to dyspnœa and râles throughout both lungs. The patient received oxygen and cedilanid. The leucocytes were 11,400 the following day; her dyspnœa was improved. The pulse rate was 116 on the day of admission, 80 after twelve hours, 60 the next day, and 44 on the evening of the third day, with occasional missed beats. The condition improved during the subsequent three weeks. The temperature ranged from $97 \cdot 8$ to $99 \cdot 2^{\circ}$ during the first fourteen days and between 97 and $98 \cdot 6^{\circ}$ during the following two weeks. A cardiogram was taken on 30/12/43 and another ten days later.

The cardiogram (Fig. 1, a-f) shows intraventricular block of the common type, with pronounced S-T displacement, suspicious of an early, recent myocardial infarct, and a peculiar type of arrhythmia. Only the latter will be discussed in this paper.

The $\mathbf{P}$ wave is small and diphasic in lead I and inverted and peaked in leads II and III. This is evidence of A-V block with nodal rhythm if the P-R interval exceeds $0.12 \mathrm{sec}$. This is true for the first beats in lead I (not shown in Fig. 1) with a P-R interval of 0.20 sec. In the following ten beats (Fig. 1 a), the $P-R$ interval gradually shortens from 0.20 to 0.08 , with an $R-R$ interval of about 1.00 sec., so that an inverted Wenckebach phenomenon appears. The next five beats (Fig. 1 b) have about the 


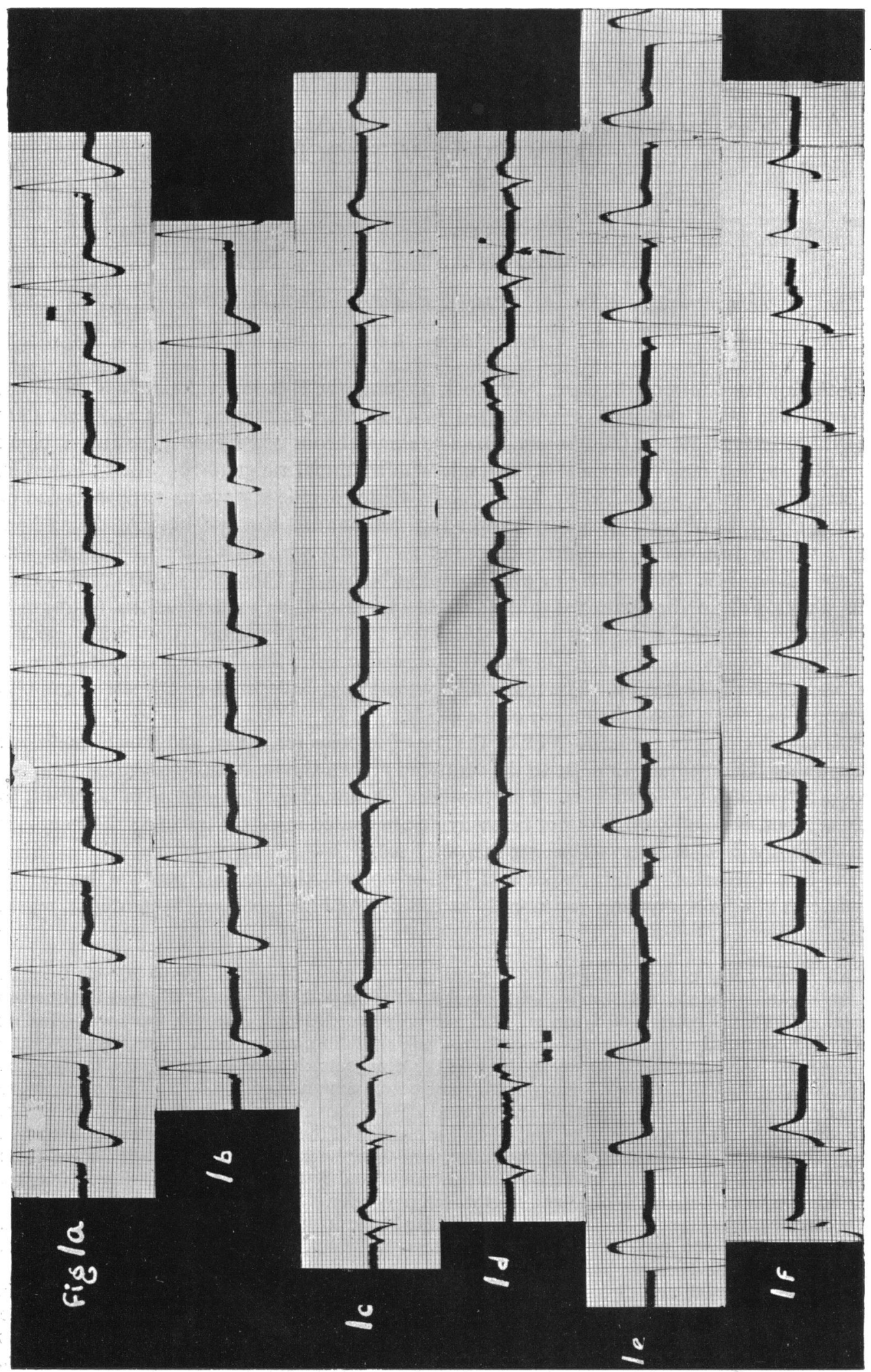


same $\mathrm{P}-\mathrm{R}$ interval of 0.08 to $0.09 \mathrm{sec}$., followed by four beats without visible $\mathrm{P}$ waves (probably fused with $Q R S)$. The $R-R$ interval remains about $1.00 \mathrm{sec}$. The last beat shows a $\mathbf{P}$ wave with a $\mathbf{P}-\mathbf{R}$ interval of 0.12 and a prolongation of the $R-R$ interval to $1.18 \mathrm{sec}$. Fig. $1 \mathrm{c}$ shows the shortening of P-R intervals in the first four beats of lead II, but more brusquely than in lead I (Fig. 1 a); in beats 3 and 4 the $P$ wave is on the descending limb of QRS with an R-P interval of 0.04 and $0.08 \mathrm{sec}$. In beats 5 to 7 no $P$ wave can be seen (probably fused with QRS), but the eighth beat is similar to the fourth. It is possible that the $P$ wave blunts the otherwise peaked $S$ wave in beats 9 and 13, which would represent an R-P interval of about $0 \cdot 1 \mathrm{sec}$. In beat 15 (beat 1 , Fig. $1 \mathrm{~d}$ ) $\mathbf{P}$ is probably on the ascending $S$ limb $(R-P=0.14 \mathrm{sec}$.), and it is immediately after the $S$ wave in the next beat $(R-P=0.16$ sec.), followed by a short run of $2: 1 \mathrm{~A}-\mathrm{V}$ block with increasing $\mathrm{P}-\mathrm{R}$ intervals from 0.08 to 0.2 before and after the interpolated ventricular beat; in the following six beats (only the first one is shown in Fig. $1 \mathrm{~d}$ ), the P-R interval is about $0.18 \mathrm{sec}$. The $R-R$ interval is about 1.00 throughout lead II except the period of $2: 1 \mathrm{~A}-\mathrm{V}$ block, where the interval increases to $2 \cdot 16$ and $2 \cdot 13$, exceeding the sum of two normal R-R intervals. In the first three beats of lead III, the P-R interval is $0 \cdot 20$ sec., followed by six beats with narrowing $P-R(0.08 \mathrm{sec}$.), in the following three beats no $P$ wave can be seen. Fig. 1 e starts with the next beat after this episode without a $P$ wave, followed by a blocked $P$ wave. The $\mathbf{R}-\mathbf{R}$ interval is $2.36 \mathrm{sec}$., significantly greater than the sum of two usual $\mathbf{R}-\mathbf{R}$ intervals. The next beat shows a P-R interval of 0.13 , the subsequent one of 0.20 (Wenckebach phenomenon). This is again followed by a period of five consecutive beats with shortening of the P-R to $0.05 \mathrm{sec}$. (inverted Wenckebach); in the last beats no $P$ waves are discernible (fused with QRS).

The first two beats of lead $\mathrm{CF}_{4}$ have an $\mathrm{R}-\mathrm{P}$ interval of $0 \cdot 18$ and an $\mathrm{R}-\mathrm{R}$ interval of about 1.0 , followed by a blocked $P$ wave and $R-R$ interval of 2.20, the same phenomenon as in Fig. $1 \mathrm{e}$ in lead III. The next beat has a P-R interval of 0.20 , gradually shortening to 0.06 in the consecutive seven beats. The R-R interval is about 0.97 . Fig. $1 \mathrm{f}$ starts with the last beat of this episode; the second, fifth, and sixth beat show a notch in the S-T segment, representing the $P$ wave with $R-P$ intervals of $0 \cdot 12$, $0 \cdot 18$, and $0 \cdot 16$, followed by a $P-R$ interval of $0 \cdot 22$ and a prolongation of the $R-R$ interval to $1 \cdot 38$, similar to the episode in Fig. $1 \mathrm{~b}$. The P-R shortens in the following beats to $0 \cdot 16$. In lead $C_{5}$ the first three beats have a P-R interval of 0.20 , which shortens to 0.08 in the consecutive five beats; no $\mathbf{P}$ wave is discernible in the following beats (fused with QRS). A cardiogram, taken after ten days, reveals only intraventricular block with prolonged P-R interval and regular rhythm.

\section{Discussion}

The contour of $\mathbf{P}$ waves, small and diphasic in lead I, inverted and peaked in leads II and III, speaks for nodal rhythm. If, according to Langendorf, Simon, and Katz (1944), the $\mathrm{P}-\mathrm{R}$ intervals exceeding $\mathbf{0 . 1 2} \mathrm{sec}$. are due to the association with $\mathrm{A}-\mathrm{V}$ block, the variation of the $\mathrm{P}-\mathrm{R}$ interval, as shown in Fig. 1, could be explained with varying degree of A-V block. This could be regarded as evidence for the view of these authors, that the presence of $A-V$ block in nodal rhythm is possible even when the $\mathrm{P}-\mathrm{R}$ interval ranges between plus 0.12 and minus $0 \cdot 19$ sec. The episodes with shortening $\mathrm{P}-\mathrm{R}$ intervals, until $\mathrm{P}$ coincides with or follows the QRS, could be explained with improving orthograde A-V conduction; when $P$ follows QRS, the forward conduction is at an optimum. This phenomenon might be regarded as due to facilitation which brings the conduction time more nearly to normal values. Occasionally, a $\mathrm{P}$ wave is blocked, in lead II in two consecutive beats, producing transitory $2: 1 \mathrm{~A}-\mathrm{V}$ block (Fig. $1 \mathrm{~d}$ ), followed by Wenckebach's phenomenon. This explains the temporary lengthening of the R-P intervals after the pauses. In lead I (Fig. 1 b) and lead $\mathrm{CF}_{2}$ (Fig. $1 \mathrm{f}$ ) a beat with a $P$ following QRS is succeeded by a beat with $P$ preceding QRS and a markedly, prolonged $\mathrm{R}-\mathrm{R}$ interval. Under the assumption of varying forward $\mathrm{A}-\mathrm{V}$ block this must be explained with an abrupt prolongation of A-V conduction.

There are, however, several difficulties encountered with this interpretation, for instance, the sudden transition from best to poorest conduction, the irrregularity with which the various episodes occur, and the rather broad range of $P-R$ and $R-P$ intervals. Perhaps these difficulties might be better explained on the assumption of nodal rhythm with varying orthograde as well as retrograde block and with a discrepancy in the time course of variations of orthograde and retrograde conduction. If the improvement of forward conduction proceeds with transitory, constant, or deteriorating retrograde conduction, and if the prolongation of forward conduction coincides with an improvement of retrograde conduction, 
a rather abrupt increase of the $\mathrm{P}-\mathrm{R}$ intervals might be produced. The assumption of varying retrograde and orthograde block with discrepancy in the time course of variations might also better explain the broad range of $\mathrm{P}-\mathrm{R}$ variations from plus 0.22 to minus $0.19 \mathrm{sec}$. The assumption of different phases of conduction disturbance in forward and retrograde $\mathrm{A}-\mathrm{V}$ block in different parts of the A-V node appears to be compatible with the demonstration of different degrees of retrograde and forward A-V block (Langendorf and Katz, 1942).

Another possible explanation is the assumption of two nodal pacemakers discharging at about the same rate, but the upper one coming progressively later. If it comes late enough, it discharges the lower pacemaker, causing the latter to discharge at a later time. This would explain the R-R prolongation at the end of lead I (Fig. $1 \mathrm{~b}$ ) and in lead $\mathrm{CF}_{2}$ (Fig. $1 \mathrm{f}$ ). When the longer pauses occur, it is assumed that the upper pacemaker discharges the lower twice in succession and is itself blocked from the ventricles. The lengthening of the $R-R$ intervals after these pauses is assumed to be due to a third discharge of the second pacemaker. A very similar mechanism has been described as interference phenomenon of a ventricular pacemaker and the sinus node. In this interpretation $P$ represents the upper pacemaker with retrograde conduction, QRS-T represents the lower pacemaker with orthograde conduction. We are inclined to favour the first interpretation. The disturbance is probably on a neurogenic basis.

\section{SUMMARY}

A case is presented with $\mathrm{P}-\mathrm{R}$ intervals varying from plus 0.22 to minus $0.19 \mathrm{sec}$. The type of $\mathbf{P}$ waves is nodal. Episodes of gradual shortening $P-R$ intervals, until $P$ follows $Q R S$, of blocked $P$ waves followed by Wenckebach's phenomenon, and abrupt transition from R-P to P-R intervals were observed. Two alternative interpretations are offered: (1) assumption of nodal rhythm with varying degree of at least forward, and possibly of both forward and retrograde conduction, or (2) assumption of two nodal pacemakers.

We wish to thank Dr. L. N. Katz, Michael Reese Hospital, Chicago, for his interest and his valuable suggestions in the preparation of this paper.

\section{REFERENCES}

Drury, A. N. (1924). Heart, 11, 405.

Langendorf, R., and Katz, L. N. (1942). Amer. Heart J., 24, 31.

- Simon, A. J., and Katz, L. N. (1944). Ibid., 27, 209.

Lewis, T. (1914). Heart, 5, 247.

Scherf, D. (1926). Wien. Arch. inn. Med., 12, 327. 